\title{
Apprentices' Resources at Work and School in Switzerland: A Person-Centred Approach
}

\author{
Fabienne Lüthi ${ }^{1 \star}$, Barbara E. Stalder ${ }^{1}$, Achim Elfering ${ }^{2}$ \\ ${ }^{1}$ Institute of Upper Secondary Education, Berne University of Teacher Education, \\ Fabrikstrasse 8, 3012 Bern, Switzerland \\ ${ }^{2}$ Department of Psychology, University of Berne, Fabrikstrasse 8, 3012 Bern, Switzerland
}

Received: 22 July 2020, Accepted: 15 July 2021

\begin{abstract}
Context: Providing learners with quality resources at work and school is a key element of apprenticeships and is essential for developing vocational competencies and successful vocational careers. Drawing on previous research on situational and personal resources, we first explored work-related and school-related resource profiles of apprentices' learning environments. We further analysed how core self-evaluations are linked to resource profiles and examined whether learners' apprenticeship satisfaction and occupational commitment varied according to the resource profiles.

Approach: We used latent profile analysis and multinomial logistic regressions, applying an integrative, person-centred approach. Our data came from the Swiss longitudinal study "Transition from Education to Employment" (TREE). The sample consisted of 1,185 apprentices enrolled in the second year of their apprenticeship.

Findings: We found four profiles of situational resources (e.g., instruction quality, climate, learning opportunities, autonomy, and demands) at the two learning locations. The profiles embodied different patterns and levels of situational resources. Two profiles were characterised by overall high or average levels of situational resources at both learning locations; the other two illustrated a stark contrast between the resources provided in the workplace and at school. Learners with higher core self-evaluations were more likely to be in profiles with
\end{abstract}

${ }^{*}$ Corresponding author: fabienne.luethi@phbern.ch 
higher situational resources. Apprentices in more beneficial profiles were more satisfied with their apprenticeships and more committed to their occupations than those in profiles with lower resources.

Conclusion: The results confirm the importance of providing apprentices with challenging, empowering, and supportive learning environments in the workplace and at vocational schools. To support learning and positive career development in apprenticeships, educators should strengthen learners' core self-evaluations to empower them to shape their learning according to their needs.

Keywords: Apprenticeship, Resources, Core Self-Evaluation, Satisfaction, Commitment, VET, Vocational Education and Training

\section{Introduction}

It is well known that learners with high situational resources (e.g., supportive colleagues and tasks that stimulate learning) and personal resources (e.g., self-efficacy) learn more and faster (Corney \& du Plessis, 2010; Zimmerman, 2000) and fare better in their careers (Stalder \& Lüthi, 2020; Taris \& Feij, 2004). Educators in vocational education and training programmes, researchers, and policy makers thus agree that all learners should be provided with favourable learning conditions, including plentiful learning opportunities or sufficient guidance and support (Filliettaz, 2011). This discussion pays increased attention to developing vocational programmes that strengthen links between school-based and workplace learning experiences (Evans et al., 2011; Mulder, 2019; Schaap et al., 2011), such as apprenticeship-based programmes, which combine workplace and vocational school learning (Fuller \& Unwin, 2011; Markowitsch \& Wittig, 2020).

Apprenticeships have been praised as optimal pathways for preparing young people for qualified work, smoothing school-to-work transitions, and promoting the development of vocational competence and occupational identity (European Union, 2016; Markowitsch \& Wittig, 2020). However, research also has highlighted the potential weaknesses and challenges of apprenticeships, such as restricted learning opportunities in the workplace or at school (Fjellström, 2014; Fuller \& Unwin, 2004; Stalder \& Schmid, 2016), a lack of cooperation between schools and companies (Gessler, 2017), and poor matches between workplaces and school curricula (Aarkrog, 2005), resulting in an insufficient alignment of what is taught, trained, and learned. This raises important questions about how learning in apprenticeships is organised, what learning resources are provided in workplaces and vocational schools, and how learners' personal resources contribute to gaining and utilising such resources for their learning. Particular challenges of apprenticeships are that methods of competence development are organised differently at work and in school (Mulder et al., 2015; Schaap et al., 2011), that 
situational resources often vary considerably within and between work and school (Fuller \& Unwin, 2004; Stalder \& Schmid, 2016), and that situational and personal resources are intertwined (Mikkonen et al., 2017). Apprentices must adapt to and profit from the learning provisions of both locations (Akkerman \& Bakker, 2012), and learners with higher personal resources might be more apt to shape their environments and more capable of handling conflicting interests between school and work.

Although many studies about learning conditions in vocational programmes exist, previous research has often focused on resources in the workplace, whereas research looking at apprentices' vocational school resources is still rare (Schaap et al., 2011). This runs counter to the assumption that resources from both learning locations, together with personal resources, are crucial for apprentices' vocational development (Mulder et al., 2015; Powers \& Watt, 2021; Stalder \& Lüthi, 2018). Moreover, previous research tended to explore specific occupational domains (Chan, 2013; Fjellström, 2014), the learning situations of adult learners (Powers, 2020), and countries, where school-based vocational programmes are predominant and apprenticeships include smaller groups of learners (Ferm, 2021; Reegård, 2018). The investigated samples might not represent the full variation of apprentices' learning situations, individual skills, and learning potentials, resulting in findings that might limit generalisability. To address these issues, this study is based on a large sample of apprentices in Switzerland, where about two thirds of all young people enrol in apprenticeships and programmes with all levels of intellectual demands are offered in all occupational sectors (Stalder, 2011; State Secretariat for Education, 2018).

In this study, we drew on the conservation of resources (COR) theory (Hobfoll et al., 2018) to propose that workplace and school resources should be joined to analyse unique resource patterns within and across learning environments, that learners' resources impact their learning environments, and that those environments, in turn, influence learners' attitudes towards their apprenticeships. We addressed these issues by exploring second-year apprentices' situational and personal resources, including a series of task-related, social, and organisational/institutional resources that have been shown to be relevant for vocational competence development (Mikkonen et al., 2017; Nisula \& Metso, 2019) and a key personal resource, core-self evaluations (Judge et al., 2003), the potential of which to shape job environments has been widely acknowledged (Judge \& Kammeyer-Mueller, 2011). Finally, we investigated whether and how being in a certain resource pattern affects two of learners' key attitudes: Apprenticeship satisfaction and occupational commitment (Messmann \& Mulder, 2015; Nägele \& Neuenschwander, 2014).

In sum, this paper makes four key contributions. First, we contribute to the emerging literature on learning in different environments of initial vocational education and training (IVET) by analysing the levels of situational resources in the workplace and vocational schools and by exploring how resources are interlinked within and across the two learning locations. 
Second, we address the call to advance knowledge by determining how learners' personal resources affect their learning environments. Third, we provide a more global picture of how workplaces and schools contribute to apprentices' vocational development, especially regarding their training satisfaction and commitment. Fourth, we provide methodological advancements over existing studies by (a) using an integrative, person-centred approach to explore patterns of situational resources in workplaces and schools; (b) examining how apprentices' personal resources predict membership in more or less favourable situational resource patterns; (c) testing whether more beneficial resource patterns are related to greater apprenticeship satisfaction and commitment; and (d) investigating a heterogeneous sample of apprentices $(\mathrm{N}=1,185)$, which enables the study of learning conditions in apprenticeships more generally. As such, our study advances an integrative understanding of the variations in resources that characterise apprentices' learning environments and their core attitudes towards their educational pathways.

\subsection{Situational Resources}

Situational resources are physical, psychological, social, or organisational characteristics of the workplace or school that are located at the level of the task (e.g., task variety), the trainer or teacher (e.g., instruction quality), coworkers or classmates (e.g., classroom climate), and the organisation or institution at large (Bakker et al., 2007; Demerouti et al., 2001). Situational resources are functional in reaching work-related goals; they foster effective learning and educational achievements and help individuals deal with challenges and demands (Bakker \& Demerouti, 2007). Regarding learning in apprenticeships, scholars have highlighted that aspects such as high-quality instruction, guidance, and support and the opportunity to work on varied tasks in a self-determined manner play key roles in the development of vocational competencies and the formation of vocational identities (Mikkonen et al., 2017; Nisula \& Metso, 2019). Apprentices with higher situational resources not only learn faster and better, they also evaluate their learning environments more positively, maintain interest and motivation, and cope better with challenges and demands that arise at work or school (Powers \& Watt, 2021; Reegård, 2015).

Demands refer to quantitative (e.g., high-workload and time-pressure) and qualitative (e.g., high task complexity) aspects of work or school, which require energy and effort to manage. Exceeding demands can be a barrier to learning (Bakker \& Demerouti, 2007), for example, when too much time pressure hampers a deeper reflection about solving a task and learning from mistakes or when tasks are too difficult, such as that apprentices might be inclined to give up early. Although there is no doubt about possible negative effects of exceeding demands, researchers also have posited that a certain amount of demands is pivotal for competence development. Demanding tasks motivate individuals to engage in learning 
(Taris \& Feij, 2004) if they value those tasks as challenging (Elfering et al., 2007; Tims et al., 2016). Reegård (2015) discovered, for example, that sales assistant apprentices found it both difficult and fun to interact with dissatisfied customers and that the challenge of handling demanding or multiple customers at once fostered the apprentices' competence development. In that sense, both quantitative and qualitative demands can function as learning resources (Taris \& Feij, 2004; Taylor \& Watt-Malcolm, 2007).

Although learning within and across different locations has been acknowledged as essential for competence development in vocational education and training (Aarkrog, 2005; Akkerman \& Bakker, 2012), research that jointly analyses resources in the workplace and at vocational schools is still rare. Moreover, studies using large samples of apprentices have been based mostly on variable-centred approaches (e.g., Elfering et al., 2016; Nisula \& Metso, 2019; Powers, 2020). These approaches typically describe how process (e.g., core self-evaluations $[\mathrm{CSE}]$ ) and outcome (e.g., satisfaction) variables are related when the effect of other variables is controlled for. Following Eye and Bogat (2006), we argue that it is necessary to use a person-centred approach and to look at patterns of learning situations within subgroups of an apprentice population.

Such an approach is supported by COR theory, which posits that resources often come "in packs" and are thus intertwined (Hobfoll et al., 2018). It has been proposed, for example, that individuals in jobs with higher learning opportunities might also have more job autonomy, more working time flexibility, and more support for their career development (Bakker et al., 2007). Studies of apprentices have confirmed that resources afforded at the level of the task, the supervisor, and the social group are often closely related. They show, for example, that learners who experience their tasks as meaningful and conducive to learning also perceive their educators as highly competent and supportive (Hofmann et al., 2014; Mikkonen et al., 2017; Stalder \& Lüthi, 2018) and that increasing task complexity goes along with increasing decision latitude and responsibility in learners (Reegård, 2015).

Whether the assumption of intertwined resources holds true only within a certain learning location (i.e., the workplace) or across different learning locations (i.e., workplace and school) has rarely been explored with greater samples of learners (see, e.g., Stalder \& Schmid, 2016). VET researchers have pointed to the different rationalities and conflicting perspectives of theoretical and practical learning (Ferm, 2021; Schaap et al., 2011) and have highlighted that learners often perceive schools and workplaces as separate environments that have little to do with each other (Akkerman \& Bakker, 2012; Reegård, 2015; Rintala et al., 2019). Current studies focused mainly on processes, methods, and means to strengthen links between theoretical knowledge, practical skills, and vocational attitudes (Aarkrog, 2005; Baartman \& de Bruijn, 2011; Evans et al., 2011).

In this study, our interest was to explore more closely whether apprentices perceive the two learning environments as aligned or contrasting. In the first case-in line with COR 
theory-high (low) resources in the workplace would be coupled with high (low) resources at school, constituting an overall favourable (unfavourable) pattern of situational resources. In the second, more plausible case, resource patterns would be homogenous within one learning location, whereas resources across workplaces and schools would appear to be unrelated. Given the lack of evidence regarding resource patterns in apprenticeships and not knowing how resources and demands in workplaces and schools are interlinked, we chose an explorative approach and asked the following.

Research questions: How many resources' profiles can be found in the data? What are their main characteristics, and how do they differ in terms of workplace and school-related resources?

\subsection{Core Self-Evaluations}

Personal resources are characteristics of the individual that refer to their personality and ability to control and affect the environment successfully (Hobfoll et al., 2018; Xanthopoulou et al., 2009). Some of the most prominent and intensively studied personal resources are CSE. CSE comprise a latent higher order trait that describes fundamental premises individuals hold about their worthiness, effectiveness, and capabilities as persons (Judge et al., 2003). They are composed of four interrelated dispositional traits: Self-esteem, generalised selfefficacy, internal locus of control, and emotional stability (Judge et al., 2003).

Research has suggested that CSE affect learners' situational resources in several ways. First, CSE influence the way individuals perceive and process information about their environment (Chang et al., 2012). Persons high in CSE tend to pay more attention to positive aspects of their situations, resulting in more favourable evaluations of their workplaces or schools (see, e.g., Judge \& Bono, 2001; Wu \& Griffin, 2012). Thus, apprentices with high CSE might perceive more or better situational resources in their workplaces and schools than other learners. Second, CSE affect individuals' learning environments directly, because persons with high CSE are self-confident and highly adaptive and trust in their abilities to influence their environments (Hirschi et al., 2015). If their jobs or workplaces do not reflect the environments they seek, they engage actively in behaviours to change their job conditions (Tims \& Bakker, 2010) and take actions to make their workplaces more rewarding (Judge \& Kammeyer-Mueller, 2011). Following this, apprentices with high CSE might search more proactively for challenging and complex tasks, ask more often for information and advice, or demand more autonomy compared to apprentices with lower CSE. This was supported, for example, in a study that found apprentices with higher CSE had higher autonomy than other learners (Elfering et al., 2016). Other researchers have reported that apprentices who successfully engaged in and completed challenging tasks felt confirmed in their self-efficacy 
and became more confident about their work; in turn, they sought actively to engage in even more challenging tasks (Fjellström, 2014; Reegård, 2015).

In sum, higher CSE may thus be linked to more situational resources because apprentices with high CSE have more optimistic views of their workplaces and schools and are more likely to shape and adapt their learning environments proactively according to their needs and interests.

As Hypothesis 1, we propose that CSE are positively related to situational resources, such as that apprentices with higher CSE are more often found in beneficial situational resource patterns than apprentices with lower CSE.

\subsection{Satisfaction and Commitment}

There is broad evidence that situational resources relate to a wide range of individual, workrelated, and educational outcomes, such as job and education satisfaction, performance, engagement, and commitment (Nägele \& Stalder, 2019; Pino-James et al., 2019; Truxillo et al., 2012). In the context of apprenticeship programmes, it is of particular importance to know how resources in the two learning locations affect learners' satisfaction with their apprenticeships and their commitments to their learned occupations. Apprenticeship satisfaction can be defined as learners' positive (or negative) evaluative judgement about their apprenticeship situation (Weiss, 2002). Occupational commitment reflects individuals' affective reaction to their occupation (Cohen, 2007) and indicates to what extent someone feels connected to a certain occupational domain (Major et al., 2012). Apprenticeship satisfaction and occupational commitment are both indicators and outcomes of high-quality education and training (Fischer, 2014). They are linked to apprentices' intentions to stay engaged, to complete their apprenticeships, and to remain in their occupational fields after graduation (Forster-Heinzer et al., 2016; Nägele \& Neuenschwander, 2014; Stalder \& Schmid, 2016).

Several studies have suggested that apprentices with more situational resources are generally more satisfied with their training (Messmann \& Mulder, 2015; Taris \& Feij, 2004) and more committed to their learned occupations (Haasler, 2007; Nägele \& Neuenschwander, 2014). In a study of apprentices in their final years of training, Kälin et al. (2000) found that learners who reported higher job control felt more valued as colleagues and were more satisfied with their apprenticeships than apprentices in less favourable environments. In contrast, a lack of situational resources might be a barrier to competence development and may correspond with negative attitudes towards the apprenticeship. For example, Stalder and Schmid (2016) showed that apprentices in low-quality apprenticeships were less satisfied with their training and less committed to their organisations than apprentices in better learning situations. Although there is broad agreement that workplaces affect apprentices' satisfaction and commitments, it is less clear whether and to what extent resources in 
vocational schools matter. Educational researchers have argued that optimal learning environments foster students' positive emotions and engagement and show that a combination of challenging and meaningful classwork, student autonomy, and high teacher support plays an important role in this process (Shernoff, 2013). Studies with apprentices have suggested, however, that resources at vocational schools seem to affect learners' general attitudes towards their apprenticeships to only a small extent (Stalder \& Carigiet Reinhard, 2014). This might be due to apprentices' identification with their roles as "young workers in training" rather than as school students (Rintala et al., 2019), resulting in a stronger bonding to the workplace (Reegård, 2015), or more simply to the fact that apprentices spend more time in their workplaces than in their schools.

Despite certain doubts about the influence of school-related resources, based on strong evidence of workplace resources, patterns of situational resources can be assumed to be related to apprentices' satisfaction and commitments. Thus, we expected that learners with overall beneficial resource patterns (especially those with high workplace resources) would evaluate their apprenticeships more positively than those in less favourable patterns.

As Hypothesis 2, we propose that apprentices in beneficial situational resource patterns experience (a) higher apprenticeship satisfaction and (b) higher occupational commitments compared to learners in less favourable patterns.

\section{Method}

\subsection{Data and Sample}

We relied on longitudinal data from the Swiss youth panel study "Transition From Education to Employment" (TREE, 2016), which is a social science data infrastructure funded mainly by the Swiss National Science Foundation and located at the University of Berne, Switzerland. The TREE study explores the postcompulsory educational and labour market pathways of more than 6,000 learners, who participated in the "Programme for International Student Assessment" (PISA) study in 2000 and were at the end of compulsory schooling at that time. Data available to date include PISA 2000 and 10 TREE waves carried out between 2001 and 2019.

For this paper, we selected a subsample of 1,185 apprentices who had completed the written survey and were at the end of the second year of their apprenticeships in 2002 or 2003. Wave-specific response rates in 2002 and 2003 were $88 \%$ and $87 \%$, respectively. Learners had a mean age of 18.1 years $(S D=0.65)$, and $43.6 \%$ were female. Two-thirds $(66.2 \%)$ of them had attended a type of lower secondary education with extended academic requirements (basic requirements: $28.8 \%$; schools without tracking: $5.0 \%$ ). Of this sample, $47.8 \%$ were in 
apprenticeships with high intellectual demands (e.g., commercial employee, IT technician), whereas $30.7 \%$ were in apprenticeships with medium intellectual demands (e.g., electrical fitter, dental assistant) and $21.5 \%$ were in apprenticeships with lower intellectual demands (e.g., retail sales assistant, cook, painter; Stalder, 2011). The apprentices lived in the German (64.9\%), French (24.0\%), and Italian (11.1\%) language regions of Switzerland.

\subsection{Measures}

Means, standard deviations, scale score reliabilities, and bivariate correlations of all variables ${ }^{1}$ are reported in Table 1.

\subsubsection{Situational Resources}

We used five indicators to assess situational resources in workplaces and at schools: Instruction quality, climate, learning opportunities, autonomy, and demands.

Trainers and teachers' instruction quality was assessed using five items each. Participants indicated their impressions of their vocational trainers and class teachers on a 4 -point scale ( $1=$ not at all true to $4=$ exactly true). Examples of items included, "If I ask a question, my vocational trainer has time to explain it" and "Usually, my teacher tells me whether I solved a task well" (TREE, 2016).

Organisational climate was assessed with three items (e.g., "My company is a place where I like to be") and climate at school was assessed with two items (e.g., "I appreciate how we treat each other in class") on a 4 -point scale ( $1=$ not at all true to $4=$ exactly true; TREE, 2016).

Learning opportunities were measured with three items each (e.g., "In the workplace/at school, I can always learn something new" and "I can fully apply my knowledge and skills"; (Prümper et al., 1995; TREE, 2016) on a 5-point scale ( $1=$ hardly ever to $5=$ very often).

Autonomy in the workplace and at school was assessed with three items, each from the Short Questionnaire for Job Analysis (e.g., "I take part in the decision-making about which tasks I have to do" and "Overall, I am free to decide in which order I organise the various steps of my work"; Prümper et al., 1995) along a 5-point scale $(1=$ strongly disagree to $5=$ strongly agree $)$.

Demands were assessed with five items, each taken from Prümper et al. (1995), focusing on qualitative demands related to the difficulty and complexity of tasks (e.g., "I must do tasks that are too complicated for me") and quantitative demands related to time pressure and workload (e.g., "I have too much to do") along a 5 -point scale $(1=$ all the time to $5=$ never $)$. For demands in the workplace, two separate scales could be built to distinguish between qualitative (three items) and quantitative (two items) demands. School demands were summarised in a single indicator.

\footnotetext{
Additional information on indicators and items can be requested from the corresponding author.
} 


\subsubsection{Core Self-Evaluations}

The TREE (2016) study assessed self-efficacy, self-esteem, and affectivity. These indicators were used to form the higher-order construct CSE (Keller \& Semmer, 2013). The fourth element, locus of control, was not assessed. Because locus of control generally tends to show weaker convergent and discriminant validity compared with the other three traits, its inclusion in CSE is controversial (Judge et al., 2003; Keller \& Semmer, 2013).

General self-efficacy was assessed with four items from the Schwarzer and Jerusalem (2002) German General Self-efficacy questionnaire. The items were rated on a 4-point scale ( 1 = strongly disagree to $4=$ strongly agree; e.g., "I can always manage to solve difficult problems if I try hard enough").

Self-esteem was measured with eight items from the Rosenberg Self-esteem Scale (Rosenberg, 1979) on a 5-point scale ( $1=$ strongly disagree to $5=$ strongly agree; e.g., "I feel that I am a person of worth").

Affectivity was assessed using 10 items from the Positive and Negative Affect Schedule (Krohne et al., 1996). Items were scored on a 5-point scale ranging from 1 (very little/not at all) to 5 (very much; e.g., "Over the last month, did you feel annoyed?"). Values inverted from negative to positive. Affectivity is typically assumed to be a proxy for neuroticism, and the two constructs are often used interchangeably (Judge et al., 2003).

\subsubsection{Satisfaction and Commitment}

Apprenticeship satisfaction was assessed with three items adapted from Bruggemann et al. (1975). Items were rated on a 7 -point scale $(1=$ very unsatisfied to $7=$ very satisfied $)$ in response to questions such as "In general, how satisfied are you with your apprenticeship?"

Occupational commitment included three items, measured on a 4-point scale ( $1=n o t$ at all true to $4=$ exactly true) (TREE, 2016). Participants indicated what they thought about their occupations (e.g., "I am proud of the occupation, I'm trained in" and "I really like the work that my occupation contains").

\subsection{Analytical Procedure}

All of the analyses were run with Mplus 8.3. Before addressing the research questions and hypotheses, a confirmatory factor analysis (CFA) was run to evaluate the empirical distinctness of the study variables and to test whether the theoretical measurement model fit the actual data. We applied the maximum likelihood estimator with robust standard errors for our analyses. Model fit was assessed using the comparative fit index (CFI), the Tucker-Lewis index (TLI), the root mean square error of approximation (RMSEA), and the standardised root 
mean square residual (SRMR). Values above .90 and .95 for the CFI and TLI, respectively, indicated adequate or excellent model fit, whereas values below .08 or .06 for the RMSEA and SRMR support acceptable or excellent model fit, respectively (Hu \& Bentler, 1999).

The situational resource measures first were examined separately for both learning locations. Regarding workplace resources, we tested a five-factor model, including demands as a single scale, and a six-factor model distinguishing between qualitative and quantitative demands. Both models showed acceptable fit (five-factor model: $\chi^{2}=669.45, d f=125$, $p<.001, \mathrm{CFI}=.91, \mathrm{TLI}=.89, \mathrm{RMSEA}=.06, \mathrm{SRMR}=.03$; six-factor model: $\chi 2=497.49, d f$ $=120, p<.001, \mathrm{CFI}=.94, \mathrm{TLI}=.92$, RMSEA $=.05, \mathrm{SRMR}=.04)$. We decided to keep the six-factor model to analyse possible effects of the two kinds of demands. We ran a five-factor model for school resources, which showed good fit $\left(\chi^{2}=370.57, d f=109, p<.001\right.$, CFI $=$ $.95, \mathrm{TLI}=.94, \mathrm{RMSEA}=.05, \mathrm{SRMR}=.03)$. Both the six-factor model for the workplace and the five-factor model for school fit the data significantly better than a one-factor model or different two- to four-factor models did. Finally, we ran an 11-factor model with all study variables and obtained acceptable fit $(\chi 2=1,350.27, d f=505, p<.001$, CFI $=.93$, TLI $=.92$, RMSEA $=.04$, SRMR $=.04)$. 
Table 1: Means, Standard Deviations, Scale Score Reliabilities, and Bivariate Correlations of all Study Variables

\begin{tabular}{|c|c|c|c|c|c|c|c|c|c|c|c|c|c|c|c|c|}
\hline Study variables & M & SD & 1 & 2 & 3 & 4 & 5 & 6 & 7 & 8 & 9 & 10 & 11 & 12 & 13 & 14 \\
\hline \multicolumn{17}{|l|}{ Situational resources } \\
\hline Trainer instruction quality & 3.99 & .85 & .88 & & & & & & & & & & & & & \\
\hline Organisational climate & 4.13 & .75 & $.53^{* * *}$ & .74 & & & & & & & & & & & & \\
\hline Learning opportunities at work & 4.05 & .68 & $.41^{* * *}$ & $.45^{* * *}$ & .76 & & & & & & & & & & & \\
\hline Autonomy in the workplace & 3.36 & .84 & $.34^{* * *}$ & $.39^{* * *}$ & $.41^{* *}$ & .70 & & & & & & & & & & \\
\hline Qualitative workplace demands & 2.07 & .61 & $-.20^{* * *}$ & $-.23^{* * *}$ & $-.07^{*}$ & $-.06^{*}$ & .58 & & & & & & & & & \\
\hline Quantitative workplace demands & 3.12 & .87 & $-.09^{*}$ & $-.12^{* * *}$ & $.11^{* * *}$ & -.03 & .27 & .56 & & & & & & & & \\
\hline Teacher instruction quality & 3.55 & .88 & .05 & $.09^{*}$ & $.18^{* * *}$ & -.02 & -.01 & .06 & .87 & & & & & & & \\
\hline School climate & 4.07 & .90 & $.06^{*}$ & $.17^{* * *}$ & $.11^{* * *}$ & .04 & -.05 & -.03 & $.22^{* * *}$ & .79 & & & & & & \\
\hline Learning opportunities at school & 3.53 & .69 & $.06^{*}$ & $.12^{* * *}$ & $.24^{* * *}$ & .05 & -.03 & .01 & $.49^{* * *}$ & $.22^{* * *}$ & .70 & & & & & \\
\hline Autonomy at school & 2.58 & .89 & .02 & .00 & .05 & .04 & $.09^{* * *}$ & .02 & $.18^{* * *}$ & $.10^{* * *}$ & $.14^{* * *}$ & .72 & & & & \\
\hline 11 School demands & 2.28 & .76 & $-.07^{*}$ & $-.12^{* * *}$ & $-.18^{* * *}$ & -.03 & $.27^{* * *}$ & .03 & $-.22^{* * *}$ & $-.19^{* * *}$ & $-.11^{* * *}$ & .00 & .81 & & & \\
\hline \multicolumn{17}{|l|}{ Personal resources } \\
\hline 12 Core self-evaluations & 3.60 & .47 & $.26^{* * *}$ & $.31^{* * *}$ & $.36^{* * *}$ & $.21^{* * *}$ & $-.30^{* * *}$ & .00 & $.16^{* * *}$ & $.23^{* * *}$ & $.21^{* * *}$ & -.01 & $-.36^{* * *}$ & .75 & & \\
\hline \multicolumn{17}{|l|}{ Positive attitudes towards the apprenticeship } \\
\hline 13 Apprenticeship satisfaction & 4.54 & 1.09 & $.46^{* * *}$ & $.53^{* * *}$ & $.53^{* *}$ & $.33^{* *}$ & $-.19^{* * *}$ & .00 & $.16^{* * *}$ & $.15^{* * *}$ & $.25^{* * *}$ & .04 & $-.19^{* * *}$ & $.34^{* *}$ & .65 & \\
\hline Occupational commitment & 3.27 & .57 & $.32^{* * *}$ & $.45^{\star * *}$ & $.44^{\star * *}$ & $.25^{\star * *}$ & $-.15^{\star * *}$ & -.02 & $.14^{* * *}$ & $.07^{\star}$ & $.17^{\star * *}$ & .00 & $-.15^{\star * *}$ & $.25^{* * *}$ & $.52^{* * *}$ & .77 \\
\hline
\end{tabular}


To examine the latent subgroups of homogenous profiles of apprentices' situational resources, we performed latent profile analysis (LPA) using the scale means of the 11 resources from the retained CFA measurement model. We compared model solutions with two to six profiles using maximum likelihood estimation. To choose the best-fitting model (Table 3), we considered the Bayesian information criterion (BIC); the sample-adjusted Bayesian information criterion (SABIC); the adjusted version of the Lo, Mendell, and Rubin likelihood-ratio test (LMRT); and the parametric bootstrapped likelihood ratio test (BLRT). A good-fitting model is usually indicated by lower BIC and SABIC values as compared to other model solutions, and the LMRT and BLRT statistics should be significant at $p<.05$ (Geiser, 2011).

To test Hypothesis 1, we started from the final LPA solution retained, and we explored the relationship between CSE and the probability of membership in the profiles. CSE was included in the final model as an auxiliary variable, and a multinomial logistic regression was run using the R3STEP command in Mplus 8.3. R3STEP shows whether an increase in an antecedent makes an individual more or less likely to belong to one profile over another. In that sense, CSE was treated as a latent profile predictor, regressed on each profile and compared to one profile that was used as reference group (Vermunt, 2010).

To test Hypothesis 2, we modelled apprenticeship satisfaction and occupational commitment as auxiliary variables added to the final profile solution using the $\mathrm{BCH}$ command in Mplus 8.3. The $\mathrm{BCH}$ procedure allowed us to test for mean level differences across the resource profiles.

\section{Results}

\subsection{Situational Resource Profiles}

The primary aim of the study was to examine whether distinctive patterns of situational resources exist in apprentices' workplaces and vocational schools (research questions). The LPA suggested dividing group situational resources into three or four profiles. We opted for the four-profile solution, given the fit criteria described above, theoretical aspects, the interpretability of the profiles, and the class sizes. It had a comparatively low SABIC $(28,451.39)$ and showed the least significant LMRT value $(225.71, p<.05)$ before LMRT values became nonsignificant (Table 2). Table 3 reports the means and standard errors of the 11 indicators in the four profiles. Figure 1 depicts the means of the four profiles. 
Table 2: Fit Indices for the LPA Models

\begin{tabular}{rcccc}
\hline $\begin{array}{c}\text { Number } \\
\text { of } \\
\text { profiles }\end{array}$ & BIC & SABIC & $\begin{array}{c}\text { LMRT } \\
\text { p-value }\end{array}$ & $\begin{array}{c}\text { BLRT } \\
\text { p-value }\end{array}$ \\
\hline 2 & 29096.87 & 28988.87 & .01 & .00 \\
3 & 28779.05 & 28632.94 & .02 & .00 \\
4 & 28635.62 & 28451.39 & .03 & .00 \\
5 & 28583.26 & 28360.91 & .17 & .00 \\
6 & 28145.83 & 28301.72 & .38 & .00 \\
\hline
\end{tabular}

Table 3: Means of the Resource Variables Across Latent Profiles

\begin{tabular}{|c|c|c|c|c|c|c|c|c|}
\hline & \multicolumn{2}{|c|}{$\begin{array}{c}\text { High resources } \\
\quad(A) \\
N=522,44.1 \%\end{array}$} & \multicolumn{2}{|c|}{$\begin{array}{l}\text { Average } \\
\text { resources (B) } \\
\mathrm{N}=448,37.8 \%\end{array}$} & \multicolumn{2}{|c|}{$\begin{array}{l}\text { High work- } \\
\text { low school } \\
\text { resources }(C) \text {, } \\
\mathrm{N}=158,13.3 \%\end{array}$} & \multicolumn{2}{|c|}{$\begin{array}{l}\text { Low work- } \\
\text { average school } \\
\text { resources (D), } \\
\mathrm{N}=57,4.8 \%\end{array}$} \\
\hline & $M$ & $S E$ & $M$ & $S E$ & $M$ & $S E$ & $M$ & $S E$ \\
\hline Trainer instruction quality & 4.42 & .06 & 3.59 & .11 & 4.35 & .10 & 2.22 & .17 \\
\hline Organisational climate & 4.56 & .05 & 3.71 & .08 & 4.42 & .14 & 2.52 & .24 \\
\hline Learning opportunities at work & 4.44 & .03 & 3.74 & .07 & 4.09 & .15 & 2.93 & .18 \\
\hline Autonomy in the workplace & 3.64 & .05 & 3.10 & .06 & 3.65 & .15 & 1.93 & .20 \\
\hline Qualitative workplace demands & 1.96 & .04 & 2.23 & .05 & 1.89 & .10 & 2.44 & .15 \\
\hline Quantitative workplace demands & 3.15 & .05 & 3.15 & .06 & 2.95 & .09 & 3.44 & .18 \\
\hline Teacher instruction quality & 4.03 & .05 & 3.38 & .11 & 2.60 & .15 & 3.80 & .19 \\
\hline School climate & 4.37 & .04 & 3.96 & .09 & 3.56 & .16 & 3.95 & .18 \\
\hline Learning opportunities at school & 3.89 & .04 & 3.38 & .08 & 2.91 & .09 & 3.52 & .13 \\
\hline Autonomy at school & 2.72 & .05 & 2.61 & .06 & 2.19 & .09 & 2.50 & .13 \\
\hline School demands & 2.07 & .04 & 2.46 & .07 & 2.40 & .14 & 2.41 & .12 \\
\hline Trainer instruction quality & 4.42 & .06 & 3.59 & .11 & 4.35 & .10 & 2.22 & .17 \\
\hline
\end{tabular}




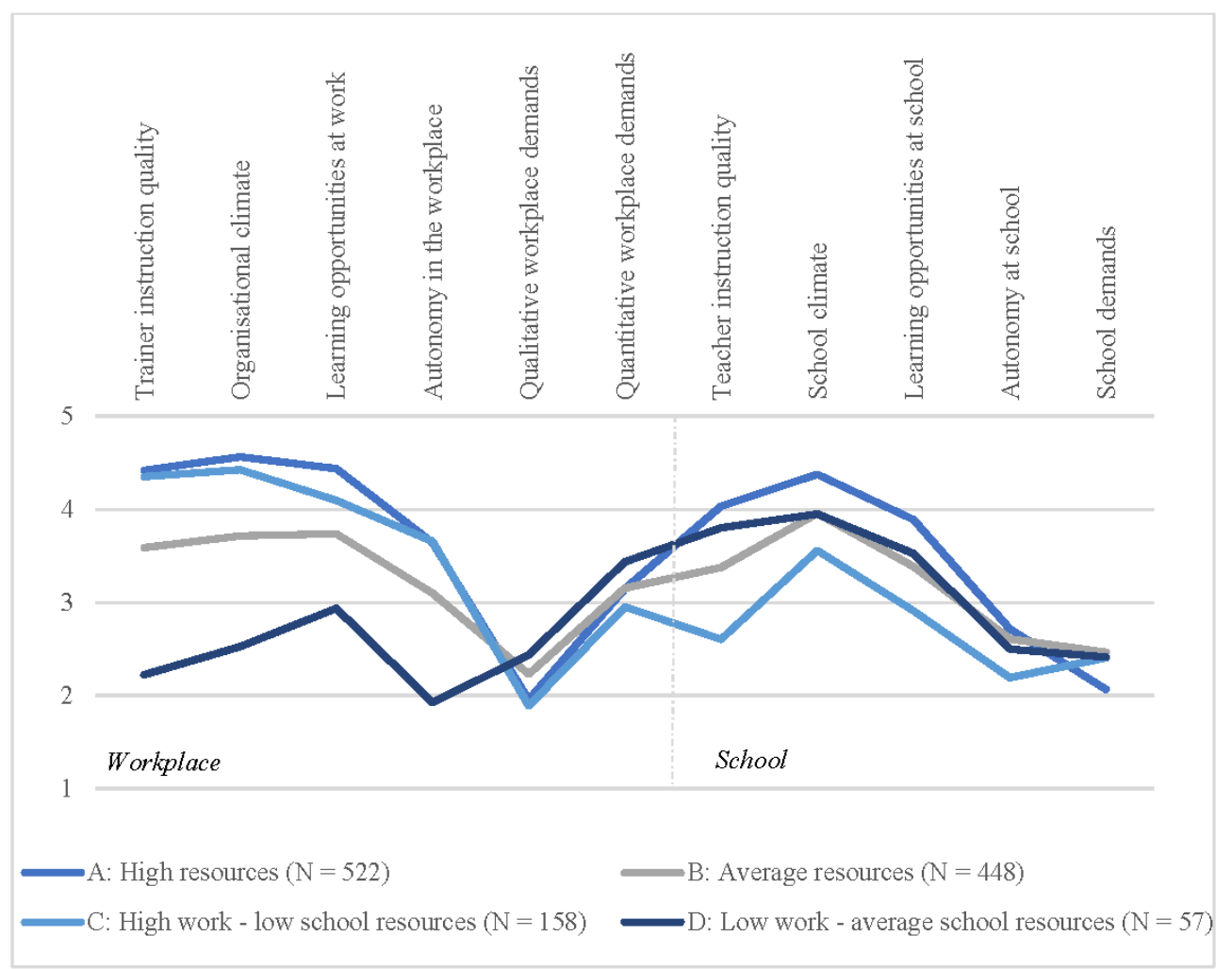

Figure 1: Four-Profile Model: Means of Apprentices' Situational Resources at Both Learning Locations

The four profiles differ with respect to the general level of resources (high-low) and to specific resource levels in the workplace and at school (e.g., low resources in the workplace and high resources at school). Overall, resources vary greatly between profiles regarding the workplace, including large differences in work-related instructional quality, climate, and learning opportunities, but less so for school (Figure 1). Workplace demands showed few variations and were low to moderate in all profiles, as did autonomy at school, which was low in all four profiles.

The profiles reveal that some apprentices estimated the resources at both locations to be similarly high (Profiles A and B), whereas others found a stark contrast between situational resources provided in the workplace versus at school (Profiles $C$ and D).

Profile A (high resources), with 522 apprentices (44.1\% of the sample), is characterised by favourable situational resources at both learning locations; that is, the instruction quality provided by trainers and teachers at work and vocational school is high, many learning opportunities are available, the organisational and school climate is conducive to learning, and apprentices enjoy high autonomy in the workplace. Overall, apprentices in this profile 
indicated that they appreciated being in the workplace and school and that interactions with VET educators and colleagues ran smoothly.

Profile B (average resources), including 448 apprentices (37.8\%), is characterised by instruction quality slightly above mid-level at both learning locations and moderate autonomy in the workplace.

Profiles C (high work-low school resources) and D (low work-average school resources) cover smaller groups of apprentices, with 158 (13.3\%) and 57 (4.8\%) learners, respectively. In Profile $\mathrm{C}$, high resources are available in the workplace (similar to Profile A), whereas resources at school seem to be limited. The instruction quality at school is much lower as compared to the other profiles, and the school climate and learning and decision-making opportunities are at lower levels than the other profiles are.

In contrast, apprentices with Profile D report very low resources in the workplace, while resources at school are average and comparable to those of Profile B. In the workplace, apprentices with Profile D seem to be very poorly instructed and guided and have limited opportunities for learning and very low autonomy.

Additional analyses were run to test whether profile membership was related to apprentices' gender, lower secondary education, the intellectual demand of the apprenticeships, and the language region. Significant differences were found for gender, with women being slightly overrepresented in Profiles C (52.5\%) and D (59.6\%) and underrepresented in Profiles A (36.8\%) and B (46.4\%), suggesting that women perceive the resources afforded by workplaces and schools as aligned less often than men do. Profiles A and C differed to some extent in terms of the intellectual demands of the apprenticeships. In Profile A, we found more learners in apprenticeships with low and medium intellectual demands (61.4\%) than expected (52.2\%), and Profile $\mathrm{C}$ had more learners in apprenticeships with high intellectual demands (69.0\%; expected $47.8 \%)$. The profiles did not differ by apprentices' lower secondary education or language region.

\subsection{CSE and Situational Resource Profiles}

Hypothesis 1 stated that apprentices with higher levels of CSE would more often be in a resource profile characterised by favourable situational resources than apprentices with lower levels of CSE would. To test this hypothesis, we regressed CSE on Profiles A, C, and D and used Profile B as a reference. The results confirm our hypothesis (Table 4). 
Table 4: Relationships Between CSE and Latent Profile Membership

\begin{tabular}{|c|c|c|c|c|c|c|c|c|c|}
\hline & \multicolumn{3}{|c|}{ Profile A vs B. } & \multicolumn{3}{|c|}{ Profile C vs B. } & \multicolumn{3}{|c|}{ Profile D vs B. } \\
\hline & Coefficient & $S E$ & OR & Coefficient & $S E$ & OR & Coefficient & $S E$ & OR \\
\hline CSE & $2.62^{* * *}$ & .29 & 24.20 & $.90^{*}$ & .43 & 5.78 & $-.76^{*}$ & .34 & .91 \\
\hline
\end{tabular}

Note. Multinomial logistic regression. Coefficients correspond to logit values. OR values above 1 (below 1 ) indicate a higher (lower) relative chance to be in Profile A, C, or D than in Profile B (reference group). ${ }^{*} p<.05,{ }^{* * *} p<.001$

In line with what we expected, apprentices with higher CSE were much more likely found in Profile A (high resources; $O R=24.2 ; p<.001$ ), somewhat more likely found in Profile C (high work-low school resources; $O R=5.78 ; p<.001$ ), and less likely found in Profile D (low work-high school resources) than in Profile B (average resources).

\subsection{Resource Profiles, Satisfaction, and Commitment}

Apprenticeship satisfaction and occupational commitment were modelled as auxiliary variables with the LPA to test differences between profile memberships (Table 5). Most of the comparisons were statistically significant, supporting Hypothesis 2.

Table 5: Comparison of Outcomes Across Latent Profiles

\begin{tabular}{lccccc|lllllll}
\hline \multicolumn{10}{c}{ Profile means } \\
\hline
\end{tabular}

Levels of apprenticeship satisfaction and occupational commitment differed in a similar manner across profiles, being highest among learners in Profile A and rather high in Profile C, followed by the profile with average resources (Profile B), and was the lowest among individuals in the profile with low work and average school resources (Profile D).

\section{Discussion}

\subsection{General Discussion}

Based on a person-centred approach, we investigated apprentices' situational resources in the workplace and at vocational schools and explored how resource profiles are related to CSE, apprenticeship satisfaction, and occupational commitment. Supporting previous research 
(Stalder \& Schmid, 2016), our results show that distinct profiles of work- and school-related resources could be identified among our large and heterogeneous sample of apprentices. We found four profiles, characterised by different levels and combinations of work- and schoolrelated resources, which varied strongly regarding the workplace and, to some extent, regarding vocational school.

We assumed that situational resources are intertwined (Hobfoll et al., 2018) and proposed two types of profiles. In the first profile, resources are interrelated across the learning locations (i.e., similar levels of resources in both locations). The second describes a profile whereby workplace and school resources are perceived as contrasting each other (i.e., dissimilar or unrelated resources). Our results show that both types occurred. In Profiles A and B, which included more than $80 \%$ of the learners, work- and school-related resources appeared to be aligned. In contrast to concerns raised in previous studies (Ferm, 2021; Schaap et al., 2011), our results thus suggest that the large majority of the apprentices perceived their workplace and school as equally conducive to learning-at both the level of the tasks that provide opportunities for learning and the social level, including supportive educators and colleagues and a favourable learning climate. This relatively high alignment might be explained by the close matching of workplace and school curricula in Swiss apprenticeships (Stalder \& Lüthi, 2018), apprentices' acknowledgement of the value and importance of both theoretical and practical knowledge, and educators who help learners to identify bridges between learning environments (Baartman \& de Bruijn, 2011; Evans et al., 2011).

The more misaligned profiles, $\mathrm{C}$ and $\mathrm{D}$, include smaller proportions of apprentices, with less favourable learning situations in vocational schools (C) or workplaces (D). Our findings may be explained by fit-theoretical approaches, which posit that newcomers must establish not only a fit to the occupation at a general level but also domain-specific fits to the organisation, the work tasks, and the supervisor (Jansen \& Kristof-Brown, 2006). While learners in Profiles A and B might have found an adequate fit to both the workplace and school, apprentices in Profile C seem to fit well to the learning situation in the workplace but fit less well to that at school. This might concern a group of apprentices who are highly engaged in practice-based learning but have limited motivation to learn at school (Mulder et al., 2015). In Profile D, the learners' interests and needs appear not to correspond to the company's learning conditions. This group of learners seem to be poorly integrated and might have to do tasks that lack challenge and meaning (Nägele \& Stalder, 2019).

Following the theoretical considerations of resource theories (Bakker \& Demerouti, 2007; Taris \& Feij, 2004), we argued that demands might function in two ways: As a barrier to or a source for learning. In the first case, learners would report low levels of learning opportunities because they are overchallenged by overly complex tasks and too much time pressure, or be underchallenged because their tasks are too easy, repetitive, or not meaningful (Fuller \& Unwin, 2004). In the second case, apprentices would experience high levels of both 
learning opportunities and demands, in the sense that the demands challenge them to gain new knowledge and skills (Messmann \& Mulder, 2015; Reegård, 2015). Our findings do not show a clear picture. Although, in Profiles C and D, having limited learning opportunities in either schools or workplaces seems to go along with low demands, demands varied only slightly between the profiles. Demands were low to moderate in all profiles, which suggests that, in general, apprentices did not seem to be overchallenged when they were surveyed. At the time of the survey, apprentices were at the end of the second year of their apprenticeship. By then, adjustment processes were well advanced (Nägele \& Neuenschwander, 2014), and most learners seemed to cope adequately with the requirements of their schools and companies. Such an interpretation is supported by the fact that we did not find a profile with low resources both in the workplace and at school. Because early leaving happens most often in the first year of apprenticeships (Bundesamt für Statistik, 2019), we might have missed the learners who started in a generally poor-fitting apprenticeship.

We were interested in determining whether school resources would matter for the profile analysis. Our results show that they contributed to the building of the profiles, but to a lesser extent than workplace resources did. This might be due to the school curricula and tight lesson plans, which regulate teacher instruction and learning processes highly. In the workplace, learning is embedded in daily work processes. It is more informal and less structured regarding the content and timing of the learning process (Nägele \& Stalder, 2019). Another explanation could be more straightforward: In Switzerland, apprentices spend more time in the workplace (3-4 days a week) than at school (1-2 days), and the organisational conditions shape their vocational identity and their commitment to the occupation (Haasler, 2007; Klotz et al., 2014; Nägele \& Neuenschwander, 2014). Thus, apprentices' appraisals of the workplace could be more pronounced and differentiated than their evaluations of the learning conditions at school, which would result in greater variation in the workplace resources.

Our results reveal that the relative chance of profile membership differed as a function of apprentices' personal resources, with higher CSE being related to more favourable resource profiles. In line with previous research, apprentices with high CSE might evaluate their situational resources more positively (Judge \& Bono, 2001; Wu \& Griffin, 2012), and they might be more confident asking for information, feedback, or more autonomy to achieve even better learning conditions (Judge \& Kammeyer-Mueller, 2011; Mikkonen et al., 2017). Such learners shape their learning environments to improve their learning situation and make it more rewarding (Hirschi et al., 2015; Judge \& Kammeyer-Mueller, 2011; Powers \& Watt, 2021). Our finding that high levels of CSE are related to better resource profiles is also in line with COR theory (Hobfoll et al., 2018), which stipulates that having resources facilitates the further accumulation of resources. While we proposed that higher CSE leads to better situational resources, a reversed effect could also be plausible. Scholars have suggested reciprocal effects of personal and situational resources, such that individuals with higher 
personal resources can secure more job or educational resources, which, in turn, would boost individuals' personal resources (Fuller \& Unwin, 2004; Shernoff, 2013; Xanthopoulou et al., 2009). Because our analytical model did not test for a reversed effect, we cannot exclude the possibility of a bidirectional relationship between CSE and situational resource profiles.

Finally, our results revealed that the latent profiles were associated with apprenticeship satisfaction and occupational commitment. In line with previous research, apprentices with high resources at both learning locations were the most satisfied and committed (Stalder \& Schmid, 2016). Interestingly, the apprentices in Profiles A and C-both with high resources in the workplace-evaluated their apprenticeships better than apprentices in the other profiles did. Workplace resources play a key role in educational success during apprenticeships and seem to affect subjective evaluations more than school-based resources do (Hofmann et al., 2014; Stalder \& Carigiet Reinhard, 2014).

\subsection{Practical Implications}

Our results show, first, that resources come in packs (Hobfoll et al., 2018) and are intertwined within and-for most apprentices-between learning locations. While the latter might be particular to Swiss apprenticeships, our findings support recommendations from previous research asking for closer matching between workplace and school curricula (Aarkrog, 2005) or stronger guidance for students in seeing the value of and bridges between different kinds of learning in different learning contexts (Evans et al., 2011).

Second, our findings confirm that high resources in both the workplace and school are crucial for apprenticeship satisfaction and occupational commitment (Nägele \& Stalder, 2019; Truxillo et al., 2012). To foster positive attitudes among apprentices towards their chosen pathway, it is important to take a global view on apprentices' learning and how learning contexts should be created. Understanding the interplay and connectedness of situational resources-specifically, their patterns-may help teachers, trainers, and policy makers to ensure high-quality programmes that provide learning-relevant resources at different levels. Beneficial resource patterns include the possibility to work on a variety of meaningful tasks throughout the apprenticeship; increasing opportunities to decide on what, when, and how certain tasks should be done; and targeted guidance and support. In addition, it is important to address the learning climate within the organisations, which should value learning and career development among all their staff, and to ensure that schools have the means and expertise to support students with different learning needs.

Considering apprentices who perceive their learning environments as detached from each other or who find themselves in less favourable resource patterns, teachers and trainers must be aware that this misalignment might be inconspicuous or invisible in the other learning 
location (Stalder \& Schmid, 2016). Thus, in such cases, it is important to strengthen the cooperation between workplaces and schools and to give apprentices the support they need.

Finally, our results emphasise the importance of fostering apprentices' personal resources. Apprentices' ability, motivation, and engagement have long been seen as prerequisites to learning (Billett, 2008; Mikkonen et al., 2017). Our results further show that apprentices can and do use their own resources to shape their learning environment. Thus, teachers and trainers can facilitate competence development and knowledge transfer from one learning environment to the other, not only directly by establishing favourable learning situations but also indirectly by empowering apprentices to change their environment proactively.

\subsection{Limitations and Further Research}

Although the current study presents several advantages over previous research, it also faces some limitations. First, we relied on a sample of apprentices in Switzerland. Our findings should be transferred to other countries and other types of apprenticeships with caution (Markowitsch \& Wittig, 2020). Second, we relied on self-report measures. Shared method bias might have affected the observed relationships between the applied measures. Future studies may include ratings from VET trainers and teachers to enrich the results and avoid potential bias. Third, as with all cross-sectional studies, it is not possible to reach clear conclusions regarding the directionality of the associations among resource profiles, CSE, and the attitudes towards apprenticeship.

The current study could not examine whether resource profiles and the chance to be in a more beneficial resource profile are more likely in certain occupational domains or if they were related to structural conditions of the apprenticeship programmes or to specific learner characteristics. Further research might explore the extent to which resource patterns vary among occupations and industries, the apprentices' age groups and educational experiences, different types and sizes of enterprises, and national VET systems (Mulder et al., 2015). Moreover, longitudinal research is needed to explore how resource patterns change over the time. Such studies are necessary to show how learners gain and maintain resources, and how they protect themselves against resource losses (Hobfoll et al., 2018). Changes to membership in profiles of work- and school-related resources during apprenticeships and after transition into employment could be explored to gain deeper insight into not only the frequency of changes but also the antecedents and outcomes of changing profile membership, in terms of satisfaction, commitment, and successful career development. 


\section{Conclusion}

This study contributed to the emerging research on learning in different IVET environments, finding distinctive situational resource profiles across and within the workplace and school and introducing the higher-order personality concept of CSE. We showed that learners in certain resource situations differ regarding their personal resources, apprenticeship satisfaction, and occupational commitment. Our research is the first to investigate situational resources using LPA, the most rigorous quantitative manner with which to explore interrelations and combinations of resources (Geiser, 2011). Our study is also one of the few studies that looks jointly at resources provided in the workplace and at school, thus taking into account that learning and competence development are important across and beyond the boundaries of specific learning environments (Akkerman \& Bakker, 2012; Mulder et al., 2015). Our results indicate that apprentices can use their personal resources to craft their learning environments. Thus, the study corroborates that both learners and educators from different settings and institutions contribute to favourable learning environments together (Billett, 2008) and thus are mutually responsible for the development of occupational skills and a meaningful career.

\section{Acknowledgement}

The Swiss panel study TREE is a social science data infrastructure mainly funded by the Swiss National Science Foundation (SNF) and located at the University of Berne. Website: https:// www.tree.unibe.ch/index_eng.html

\section{References}

Aarkrog, V. (2005). Learning in the workplace and the significance of school-based education: A study of learning in a Danish vocational education and training programme. International Journal of Lifelong Education, 24(2), 137-147. https://doi.org/10.1080/02601370500056268

Akkerman, S. F., \& Bakker, A. (2012). Crossing boundaries between school and work during apprenticeships. Vocations and Learning, 5(2), 153-173. https://doi.org/10.1007/s12186-011-9073-6

Baartman, L. K. J., \& de Bruijn, E. (2011). Integrating knowledge, skills and attitudes: Conceptualising learning processes towards vocational competence. Educational Research Review, 6(2), 125-134. https://doi.org/10.1016/j.edurev.2011.03.001

Bakker, A. B., \& Demerouti, E. (2007). The job demands-resources model: State of the art. Journal of Managerial Psychology, 22(3), 309-328. https://doi.org/10.1108/02683940710733115

Bakker, A. B., Hakanen, J. J., Demerouti, E., \& Xanthopoulou, D. (2007). Job resources boost work engagement, particularly when job demands are high. Journal of Educational Psychology, 99(2), 274-284. https://doi.org/10.1037/0022-0663.99.2.274 
Billett, S. (2008). Learning through work: Exploring instances of relational interdependencies. International Journal of Educational Research, 47(4), 232-240. https://doi.org/10.1016/j.ijer.2008.07.006

Bruggemann, A., Groskurth, P., \& Ulich, E. (1975). Arbeitszufriedenheit. Hans Huber.

Bundesamt für Statistik, B. (2019). Lehrvertragsauflösung, Wiedereinstieg, Zertifikationsstatus. Resultate zur dualen beruflichen Grundbildung (EBA und EFZ), Ausgabe 2019. BFS.

Chan, S. (2013). Learning through apprenticeship: Belonging to a workplace, becoming and being. Vocations and Learning, 6(3), 367-383. https://doi.org/10.1007/s12186-013-9100-x

Chang, C.-H. D., Ferris, D. L., Johnson, R. E., Rosen, C. C., \& Tan, J. A. (2012). Core self-evaluations: A review and evaluation of the literature. Journal of Management, 38(1), 81-128. https://doi. org/10.1177/0149206311419661

Cohen, A. (2007). Dynamics between occupational and organizational commitment in the context of flexible labor markets: A review of the literature and suggestions for a future research agenda. Universität Bremen, Institut Technik und Bildung.

Corney, T., \& du Plessis, K. (2010). Apprentices' mentoring relationships. The role of 'significant others' and supportive relationships across the work-life domains. Youth Studies Australia, 29(3), 18-26.

Demerouti, E., Bakker, A. B., Nachreiner, F., \& Schaufeli, W. B. (2001). The job demands-resources model of burnout. Journal of Applied Psychology, 86(3), 499-512. https://doi.org/10.1037/00219010.86.3.499

Elfering, A., Keller, A. C., Berset, M., Meier, L. L., Grebner, S., Kälin, W., Monnerat, F., Tschan, F., \& Semmer, N. K. (2016). Taking the chance: Core self-evaluations predict relative gain in job resources following turnover. Springerplus, 5(1702), 1-10. https://doi.org/10.1186/s40064-016-3365-0

Elfering, A., Semmer, N. K., Tschan, F., Kälin, W., \& Bucher, A. (2007). First years in job: A threewave analysis of work experience. Journal of Vocational Behavior, 70(1), 97-115. https://doi. org/10.1016/j.jvb.2006.07.001

European Union. (2016). The Riga Conclusions. European cooperation in vocational education and training. https://doi.org/10.2767/437732

Evans, K., Guile, D., \& Harris, J. (2011). Rethinking work-based learning: For education professionals and professionals who educate. In M. Malloch, L. Cairns, K. Evans \& B. N. O'Connor (Eds.), The SAGE Handbook of Workplace Learning (pp. 149-162). SAGE Publications Ltd. https://doi. org/10.4135/9781446200940.n11

Eye, A. v., \& Bogat, G. A. (2006). Person-oriented and variable-oriented research: Concepts, results, and development. Merrill-Palmer Quarterly, 52(3), 390-420. https://doi.org/10.1353/mpq.2006.0032

Ferm, L. (2021). Vocational students' ways of handling the academic/vocational divide. International Journal for Research in Vocational Education and Training, 8(1), 1-20. https://doi.org/10.13152/ ijrvet.8.1.1

Filliettaz, L. (2011). Collective guidance at work: A resource for apprentices? Journal of Vocational Education \& Training, 63(3), 485-504. https://doi.org/10.1080/13636820.2011.580359

Fischer, M. (2014). Qualität in der Berufsausbildung. Anspruch und Wirklichkeit. Bertelsmann.

Fjellström, M. (2014). Vocational education in practice: A study of work-based learning in a construction programme at a Swedish upper secondary school. Empirical Research in Vocational Education and Training, 6(2). https://doi.org/10.1186/1877-6345-6-2

Forster-Heinzer, S., Holtsch, D., Rohr-Mentele, S., \& Eberle, F. (2016). Do they intend to stay? An empirical study of commercial apprentices' motivation, satisfaction and intention to remain within 
the learned occupation. Empirical Research in Vocational Education and Training, 8(1). https://doi. org/10.1186/s40461-016-0041-0

Fuller, A., \& Unwin, L. (2004). Expansive learning environments: Integrating personal and organisational development. In H. Rainbird, A. Fuller \& A. Munro (Eds.), Workplace learning in context (pp. 126-144). https://doi.org/10.4324/9780203571644

Fuller, A., \& Unwin, L. (2011). Apprenticeship as an evolving model of learning. Journal of Vocational Education \& Training, 63(3), 261-266. https://doi.org/10.1080/13636820.2011.602220

Geiser, C. (2011). Datenanalyse mit Mplus. Eine anwendungsorientierte Einführung (2nd Ed.). VS. https://doi.org/10.1007/978-3-531-93192-0

Gessler, M. (2017). The lack of collaboration between companies and schools in the German dual apprenticeship aystem: Historical background and recent data. International Journal for Research in Vocational Education and Training, 4(2), 164-195. https://doi.org/10.13152/IJRVET.4.2.4

Haasler, B. (2007). Apprentices' experiences of occupational and organisational commitment: An empirical investigation in a German automobile company. In A. Brown, S. Kirpal \& F. Rauner (Eds.), Identities at Work (pp. 261-284). Springer. https://doi.org/10.1007/978-1-4020-4989-7_10

Hirschi, A., Herrmann, A., \& Keller, A. C. (2015). Career adaptivity, adaptability, and adapting: A conceptual and empirical investigation. Journal of Vocational Behavior, 87, 1-10. https://doi. org/10.1016/j.jvb.2014.11.008

Hobfoll, S. E., Halbesleben, J., Neveu, J.-P., \& Westman, M. (2018). Conservation of resources in the organizational context: The reality of resources and their consequences. Annual Review of Organizational Psychology and Organizational Behavior, 5(1), 103-128. https://doi.org/10.1146/annurevorgpsych-032117-104640

Hofmann, C., Stalder, B. E., Tschan, F., \& Häfeli, K. (2014). Support from teachers and trainers in vocational education and training: The pathways to career aspirations and further career development. International Journal for Research in Vocational Education and Training, 1(1), 1-20. https://doi. org/10.13152/IJRVET.1.1.5

Hu, L.-t., \& Bentler, P. M. (1999). Cutoff criteria for fit indexes in covariance structure analysis: Conventional criteria versus new alternatives. Structural Equation Modeling, 6(1), 1-55. https://doi. org/10.1080/10705519909540118

Jansen, K. J., \& Kristof-Brown, A. L. (2006). Toward a multidimensional theory of person-environment fit. Journal of Managerial Issues, 18(2), 193-212.

Judge, T. A., \& Bono, J. E. (2001). Relationship of core self-evaluations traits-self-esteem, generalized self-efficacy, locus of control, and emotional stability-with job satisfaction and job performance: A meta-analysis. Journal of Applied Psychology, 86(1), 80-92. https://doi.org/10.1037/00219010.86.1.80

Judge, T. A., Bono, J. E., \& Thoresen, C. J. (2003). The core self-evaluation scale: Development of a measure. Personnel Psychology, 56(2), 303-331. https://doi.org/10.1111/j.1744-6570.2003. tb00152.x

Judge, T. A., \& Kammeyer-Mueller, J. D. (2011). Implications of core self-evaluations for a changing organizational context. Human Resource Management Review, 21(4), 331-341. https://doi. org/10.1016/j.hrmr.2010.10.003

Kälin, W., Semmer, N. K., Elfering, A., Tschan, F., Dauwalder, J.-P., Heunert, S., \& Crettaz von Roten, F. (2000). Work characteristics and well-being of Swiss apprentices entering the labor market. Swiss Journal of Psychology, 59(4), 272-290. https://doi.org/10.1024//1421-0185.59.4.272 
Keller, A. C., \& Semmer, N. K. (2013). Changes in situational and dispositional factors as predictors of job satisfaction. Journal of Vocational Behavior, 83(1), 88-98. https://doi.org/10.1016/j. jvb.2013.03.004

Klotz, V. K., Billett, S., \& Winther, E. (2014). Promoting workforce excellence: Formation and relevance of vocational identity for vocational educational training. Empirical Research in Vocational Education and Training, 6(6). https://doi.org/10.1186/s40461-014-0006-0

Krohne, H. W., Egloff, B., Kohlmann, C.-W., \& Tausch, A. (1996). Untersuchungen mit einer deutschen Version der "Positive and Negative Affect Schedule" (PANAS). Diagnostica, 42(2), 139-156. https://doi.org/10.1037/t49650-000

Major, D. A., Morganson, V. J., \& Bolen, H. M. (2012). Predictors of cccupational and organizational commitment in information technology: Exploring gender differences and similarities. Journal of Business and Psychology, 28(3), 301-314. https://doi.org/10.1007/s10869-012-9282-5

Markowitsch, J., \& Wittig, W. (2020). Understanding differences between apprenticeship programmes in Europe: Towards a new conceptual framework for the changing notion of apprenticeship. Journal of Vocational Education \& Training, 1-22. https://doi.org/10.1080/13636820.2020.1796766

Messmann, G., \& Mulder, R. H. (2015). Conditions for apprentices' learning activities at work. Journal of Vocational Education \& Training, 67(4), 578-596. https://doi.org/10.1080/13636820.2015.1094 745

Mikkonen, S., Pylväs, L., Rintala, H., Nokelainen, P., \& Postareff, L. (2017). Guiding workplace learning in vocational education and training: A literature review. Empirical Research in Vocational Education and Training, 9(1). https://doi.org/10.1186/s40461-017-0053-4

Mulder, M. (2019). Foundations of competence-based vocational education and training. In S. McGrath, M. Mulder, J. Papier \& R. Suart (Eds.), Handbook of Vocational Education and Training (pp. 1-26). Springer. https://doi.org/10.1007/978-3-319-49789-1_65-2

Mulder, R. H., Messmann, G., \& König, C. (2015). Vocational education and training: Researching the relationship between school and work. European Journal of Education, 50(4), 497-512. https://doi. org/10.1111/ejed.12147

Nägele, C., \& Neuenschwander, M. P. (2014). Adjustment processes and fit perceptions as predictors of organizational commitment and occupational commitment of young workers. Journal of Vocational Behavior, 85(3), 385-393. https://doi.org/10.1016/j.jvb.2014.08.011

Nägele, C., \& Stalder, B. E. (2019). Motivation and engagement of learners in organizations. In S. McGrath, M. Mulder, J. Papier \& R. Suart (Eds.), Handbook of vocational education and training: Developments in the changing world of work (pp. 847-861). Springer. https://doi.org/10.1007/9783-319-49789-1_106-1

Nisula, A.-M., \& Metso, S. (2019). Factors fostering vocational students' workplace learning success in the real workplace environment. Journal of Education and Work, 32(6-7), 552-569. https://doi.org /10.1080/13639080.2019.1673884

Pino-James, N., Shernoff, D. J., Bressler, D. M., Larson, S. C., \& Sinha, S. (2019). Instructional interventions that support student engagement: An international perspective. In J. A. Fredricks, A. L. Reschly \& S. L. Christenson (Eds.), Handbook of Student Engagement Interventions (pp. 103-119). Academic Press. https://doi.org/10.1016/b978-0-12-813413-9.00008-5

Powers, T. E. (2020). Motivated apprentices: The value of workplace and trade school. Journal of Education and Work, 33(1), 81-97. https://doi.org/10.1080/13639080.2020.1716309 
Powers, T. E., \& Watt, H. M. G. (2021). Understanding why apprentices consider dropping out: Longitudinal prediction of apprentices' workplace interest and anxiety. Empirical Research in Vocational Education and Training, 13(1). https://doi.org/10.1186/s40461-020-00106-8

Prümper, J., Hartmannsgruber, K., \& Frese, M. (1995). KFZA. Kurzfragebogen zur Arbeitsanalyse. Zeitschrift für Arbeits- und Organisationspsychologie, 39(3), 125-131.

Reegård, K. (2015). Sales assistants in the making: Learning through responsibility. Vocations and Learning, 8(2), 117-133. https://doi.org/10.1007/s12186-015-9129-0

Reegård, K. (2018). Correction to: Sales assistants in the making: Learning through responsibility. Vocations and Learning, 12(2), 341-341. https://doi.org/10.1007/s12186-018-9198-y

Rintala, H., Nokelainen, P., \& Pylväs, L. (2019). Informal workplace learning. In J. A. Fredricks, A. L. Reschly \& S. L. Christenson (Eds.), Handbook of Vocational Education and Training (pp. 1-14). Academic Press. https://doi.org/10.1007/978-3-319-49789-1_97-1

Rosenberg, M. (1979). Conceiving the self. Basic Books.

Schaap, H., Baartman, L., \& de Bruijn, E. (2011). Students' learning processes during school-based learning and workplace learning in vocational education: A review. Vocations and Learning, 5(2), 99-117. https://doi.org/10.1007/s12186-011-9069-2

Schwarzer, R., \& Jerusalem, M. (2002). Das Konzept der Selbstwirksamkeit. In M. Jerusalem \& H. Diether (Eds.), Selbstwirksamkeit und Motivationsprozesse in Bildungsinstitutionen (pp. 28-53). Beltz.

Shernoff, D. J. (2013). Optimal learning environments to promote student engagement. Springer. https:// doi.org/10.1007/978-1-4614-7089-2

Stalder, B. E. (2011). The intellectual demands of initial vocational education and training in Switzerland. Ratings for the period 1999-2005. University of Basel, Institute of Sociology. https://doi. org/10.7892/boris. 131086

Stalder, B. E., \& Carigiet Reinhard, T. (2014). Ausbildungsqualität aus Sicht von Lernenden und Betrieben in der Schweiz. In M. Fischer (Ed.), Qualität in der Berufsausbildung - Anspruch und Wirklichkeit (pp. 97-118). Bertelsmann.

Stalder, B. E., \& Lüthi, F. (2018). Learning within and beyond the borders of schools and workplaces. In L. Moreno Herrera, M. Teräs \& P. Gougoulakis (Eds.), Vocational education \& training - the world of work and teacher education. Emergent issues in research on vocational education \& training Vol. 3. Premiss förlag.

Stalder, B. E., \& Lüthi, F. (2020). Job resources and career success of IVET graduates in Switzerland: A different approach to exploring the standing of VET. Journal of Vocational Education \& Training, 72(2), 189-208. https://doi.org/10.1080/13636820.2020.1721735

Stalder, B. E., \& Schmid, E. (2016). Lehrvertragsauflösung und Ausbildungserfolg - kein Widerspruch. hep.

State Secretariat for Education, R. a. I., SERI. (2018). Swiss Participation in European Research Framework Programmes. State Secretariat for Education, Research and Innovation

Taris, T. W., \& Feij, J. A. (2004). Learning and strain among newcomers: A three-wave study on the effects of job demands and job control. The Journal of Psychology, 138(6), 543-563. https://doi. org/10.3200/JRLP.138.6.543-563

Taylor, A., \& Watt-Malcolm, B. (2007). Expansive learning through high school apprenticeship: Opportunities and limits. Journal of Education and Work, 20(1), 27-44. https://doi. org/10.1080/13639080601137734 
Tims, M., \& Bakker, A. B. (2010). Job crafting: Towards a new model of individual job redesign. $S A$ Journal of Industrial Psychology, 36(2), 1-9. https://doi.org/10.4102/sajip.v36i2.841

Tims, M., Derks, D., \& Bakker, A. B. (2016). Job crafting and its relationships with person-job fit and meaningfulness: A three-wave study. Journal of Vocational Behavior, 92, 44-53. https://doi. org/10.1016/j.jvb.2015.11.007

TREE. (2016). Documentation on the first TREE cohort (TREE1), 2000-2016. TREE.

Truxillo, D. M., Cadiz, D. M., Rineer, J. R., Zaniboni, S., \& Fraccaroli, F. (2012). A lifespan perspective on job design: Fitting the job and the worker to promote job satisfaction, engagement, and performance. Organizational Psychology Review, 2(4), 340-360. https://doi.org/10.1177/2041386612454043

Vermunt, J. K. (2010). Latent class modeling with covariates: Two improved three-step approaches. Political Analysis, 18(04), 450-469. https://doi.org/10.1093/pan/mpq025

Weiss, H. M. (2002). Deconstructing job satisfaction. Separating evaluations, beliefs and affective experiences. Human Resource Management Review, 12(2), 173-194. https://doi.org/10.1016/S10534822(02)00045-1

Wu, C.-H., \& Griffin, M. A. (2012). Longitudinal relationships between core self-evaluations and job satisfaction. Journal of Applied Psychology, 97(2), 331-342. https://doi.org/10.1037/a0025673

Xanthopoulou, D., Bakker, A. B., Demerouti, E., \& Schaufeli, W. B. (2009). Reciprocal relationships between job resources, personal resources, and work engagement. Journal of Vocational Behavior, 74(3), 235-244. https://doi.org/10.1016/j.jvb.2008.11.003

Zimmerman, B. J. (2000). Self-efficacy: An essential motive to learn. Contemporary Educational Psychology, 25(1), 82-91. https://doi.org/10.1006/ceps.1999.1016

\section{Biographical Notes}

Fabienne Lüthi is a PhD student at the Berne University of Teacher Education, Switzerland. Her research focuses on personal and situational resources and the interrelation between school-based and workplace learning in dual vocational education and training programs and on career development and success.

Dr Barbara E. Stalder is a professor at the Berne University of Teacher Education, Switzerland. Her research interests focus on student engagement and learning, career development in VET, and career success over the life course.

Dr Achim Elfering is an extraordinary professor of work and organisational psychology at the University of Berne, Switzerland, and is also affiliated with the National Centre of Competence in Research, Affective Science, University of Geneva; CISA, Geneva; and the UniDistance Suisse, Brig, Switzerland. His research topics are occupational stress and health, work and emotions, and safety at work. 